\title{
TOP 10 WAYS TO IMPROVE THE COMMUNICATION SKILLS
}

Effective communication is one of the most important life skills we can learn yet one we don't usually put a lot of effort into. Whether you want to have better conversations in your social life or get your ideas across better at work, here are some essential tips for learning to communicate more effectively.

\section{Watch Your Body Language}

You tell your partner you're open to discussion but your arms are crossed; say you're listening but haven't looked up from your phone yet. Our non-verbal and non-written cues often reveal more than we think they do. Whether it's how you make eye contact or how you hold yourself during a video interview, don't forget that you're constantly communicating even when you're not saying a word. One strange way to tap into your body for better communication , Think about your toes. Or adopt a power pose if you need to boost your confidence before a big talk. Or learn how to read other people's body language so you can respond appropriately.

\section{Get Rid of Unnecessary Conversation Fillers}

Um's and ah's do little to improve your speech or everyday conversations. Cut them out to be more persuasive and feel or appear more confident. One way is to start keeping track of when you say words like "um" or "like." You could also try taking your hands out of your pockets or simply relaxing and pausing before you speak. Those silences seem more awkward to you than they do to others, trust us.

\section{Have a Script for Small Talk and Other Occasions}

Small talk is an art that not many people have mastered. For the inevitable, awkward silences with people you hardly know, it helps to have a plan. The FORD (family, occupation, recreation dreams) method might help you come up with topics to discuss, and you can also turn small talk into conversation by sharing information that could help you and the other person find common ground. Hey, all that small talk could make you happier in the long run.

\section{Tell a Story}

Stories are powerful. They activate our brains, make presentations suck less, make us more persuasive, and can even help us ace interviews. Learn the secrets of becoming a phenomenal storyteller with these rules from Pixar or by simply using the word "but" more to structure your narrative. Everyone's got at least one great story in them.

\section{Ask Questions and Repeat the Other Person}

Let's face it, we've all drifted off when someone else was talking or misheard the other person. Asking questions and repeating the other person's last few words shows you're interested in 
what they say, keeps you on your toes, and helps clarify points that could be misunderstood (e.g., "So to recap, you're going to buy the tickets for Saturday?").

It also helps for small talk and to fill in awkward silences. Instead of trying to stir up conversation on mundane topics like the weather, ask the other person questions (e.g., "Got any plans for the summer?" or "What are you reading lately?") and engage in their answers. It's more important to be interested than to be interesting.

\section{Put Away the Distractions}

It's pretty rude to use your phone while someone's talking to you or you're supposed to be hanging out with them. Maybe we can't get rid of all our distractions or put away technology completely, but just taking the time to look up could vastly improve our communication with each other.

\section{Your Message to Your Audience}

The best communicators adjust how they talk based on whom they're speaking to; you'd probably use a different style of communication with co-workers or your boss compared to when you're speaking with your significant other, kids, or elders. Always try to keep the other person's perspective in mind when you try to get your message across.

\section{Be Brief Yet Specific}

There's actually a BRIEF acronym-Background, Reason, Information, End, Follow-up-to help you keep your emails short without leaving anything out. It's a good policy for both written and verbal communication, Clear and concise are two of the $7 \mathrm{Cs}$ of communication, along with concrete, correct, coherent, complete, and courteous.

\section{Up Your Empathy}

Communication is a two-way street. If you practice taking the opposing viewpoint, you can reduce the difficulty and anxiety that sometimes arises when trying to truly communicate with others. (For example, knowing what your significant other really means when she says she's too tired to talk.) Developing empathy helps you better understand even the unspoken parts of your communication with others, and helps you respond more effectively.

\section{Listen, Really Listen}

Finally, going hand-in-hand with most of the points above, the best thing you can do to improve your communication skills is to learn to really listen - to pay attention and let the other person talk without interrupting. It's hard work, we know, but "A good conversation is a bunch of words elegantly connected with listening." Then, even if your communication styles don't match, at least you're both working off the same page. And hopefully the other person will be attentively listening to you too.

Direct assertive expression makes for clear communication and can help boost self-esteem and decision-making. Being assertive means expressing your thoughts, feelings, and needs in an open and honest way, while standing up for your-self and respecting others. It does not mean being hostile, aggressive, or demanding. Effective communication is always about understanding the other person, not about winning an argument or forcing your opinions on others. 


\section{WAYS TO IMPROVE THE COMMUNICATION SKILLS}

Effective Communication Skills are the Mark of an Achiever.

Have you ever blown a deal, a job interview, a promotion, or a relationship, because of your communication skills, Maybe you just couldn't think of the right words to say. Has your tongue ever seemed disconnected from your brain, You can easily overcome anxiety, expand your abilities, and empower yourself for success by using these tips.

1) Listen without judgment. The key to good communication is listening well. Save your judging for later after you have heard and understood what was said.

2) Listen with the willingness to be swayed to the other person's opinion. No obligation to actually being swayed, but stay open to the option.

3) Listen without thinking about what you will say next. Take time before you respond.

4) Do not be invested in being right. Being right is not the point. If you must be right, you are not able to listen nor communicate because you have set up a barrier already. If you are always right that means the other person is always wrong. That cannot be true.

5) If your mind wanders, ask for repetition. We all are subject to distraction. Try to stay focused.

6) In all cases repeat back what you heard and ask if it is correct.

7) Listen to yourself. Find quiet moments and pay attention to what you are hearing from yourself. Does your body tighten up about certain issues. Body language is not something to read only in other people.

8) Say it honestly, but with consideration for the listener's feelings. Be polite, respectful and sincere.

9) Understand and acknowledge that most things are not black or white, but somewhere in a gray area. Get comfortable with gray.

10) Have integrity and build trust. Don't say what you don't mean. Don't promise what you won't or can't fulfill. Follow through with any commitments you make.

Good listening skills take practice. Specific coaching may be necessary if you find you have communication issues with your boss, colleagues, subordinates, partners or personal relationships. 